\title{
ZINC OXIDE - A UNIQUE MATERIAL FOR ADVANCED PHOTOVOLTAIC SOLAR CELLS
}

\author{
Soňa Flickyngerová — Vladimír Tvarožek — Pavol Gašpierik
}

\begin{abstract}
A novel approach to the preparation of thin films by using RF diode sputtering was developed. In one deposition run, thin films of doped $\mathrm{ZnO}:(\mathrm{Al}, \mathrm{Ga})$ were obtained with different structural, optical and electrical properties. $\mathrm{ZnO}: \mathrm{Al}$ films of low resistivities in order of $10^{-3} \Omega \mathrm{cm}$ and high optical transmittances about $93 \%$ have appeared the most suitable for photovoltaic applications.
\end{abstract}

K e y w or d s: thin film solar cell, Zinc oxide, sputtering

\section{INTRODUCTION}

Transparent conducting oxides (TCOs) based on $\mathrm{ZnO}$ exhibit unique properties (optoelectronic, pyroelectric, chemoelectric, acoustoelectric) which are applicable in microsensors and actuators. Use of $\mathrm{ZnO}$ is attractive from technical and economical point of view: compatibility with large amount of materials, low price, environmentally friendly and easy implementation in microelectronic technology.

TCOs based on $\mathrm{ZnO}$ are also promising for application in thin-film solar photovoltaic cells (PVCs) (Morkoc and Ozgur 2009). Desired parameters of $\mathrm{ZnO}$ and doped $\mathrm{ZnO}:(\mathrm{Al}, \mathrm{Ga})$ thin films are given by their role in superstrate configuration of Si solar cell [6]: the light enters the cell through the glass substrate where $p$ - $i$ - $n$ absorber thin-film structure is placed between two TCO layers with back metal contact, Fig. 1. The upper front contact TCO layer should fulfil several important requirements: high transparency in VIS/near IR solar spectrum; high electrical conductivity; suitable surface texture in order to enhance light scattering and absorption inside the cell; high chemical stability and adhesion to silicon. Optimization of the front contact TCO has proven to be crucial for getting the high cell efficiency.

We present a novel approach to the preparation of $\mathrm{ZnO}: \mathrm{Al}$ and $\mathrm{ZnO}: \mathrm{Ga}$ thin films with different properties in one deposition run by using RF diode sputtering.

\section{SPUTTERING OF THIN FILMS}

RF sputtering is owning several advantages in comparison with the other physical and chemical deposition methods: a low-temperature ionassisted deposition of metals, semiconductors, insulators, the before/post deposition modification of substrate/thin - film surface by ions on the micro-/nano- level; change of deposition rate in wide range ( 0.1 to $10 \mathrm{~nm} / \mathrm{s})$; to control further parameters which are important for thin film growth (substrate temperature, plasma density, composition of working gas, ion bombardment of film during deposition). In addition there is a significant contribution of secondary electron bombardment to the atomic scale heating of the film when it is prepared by the RF diode sputtering.

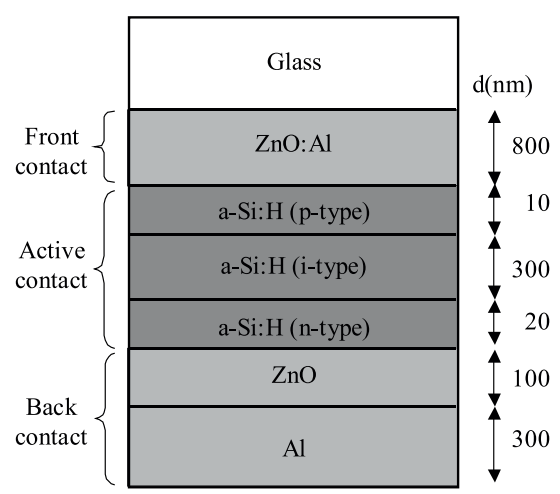

Fig. 1. "Superstrate" configuration of thin film solar cell

In general, sputter deposition is determined by complex processes proceeded: (a) at the target bombarded by energetic ions, (b) in the low-temperature plasma, (c) on the surface of substrate and growing film. In general, thin film growth is influenced by the kinetic energy of coating species on the substrate - in addition to substrate temperature a total energy flux is acting to the substrate and growing thin film. It depends mainly on the amount and the energy of: (i) sputtered coating species, (ii) energetic neutral working gas atoms (neutralized and reflected at the target), (iii) energetic secondary electrons emitted from the target, (iv) negative ions coming from

\footnotetext{
* Department of Microelectronics, Slovak University of Technology, Ilkovičova 3, 81219 Bratislava, Slovakia, sona.flickyngerova@stuba.sk, vladimir.tvarozek@stuba.sk, pavol.gaspierik@stuba.sk
} 


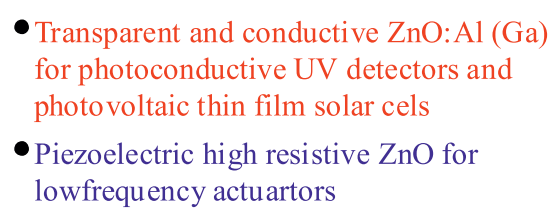

- Piezoelectric and transparent $\mathrm{ZnO}$ for SAW mixing used in optoelectronic blood diagnosis

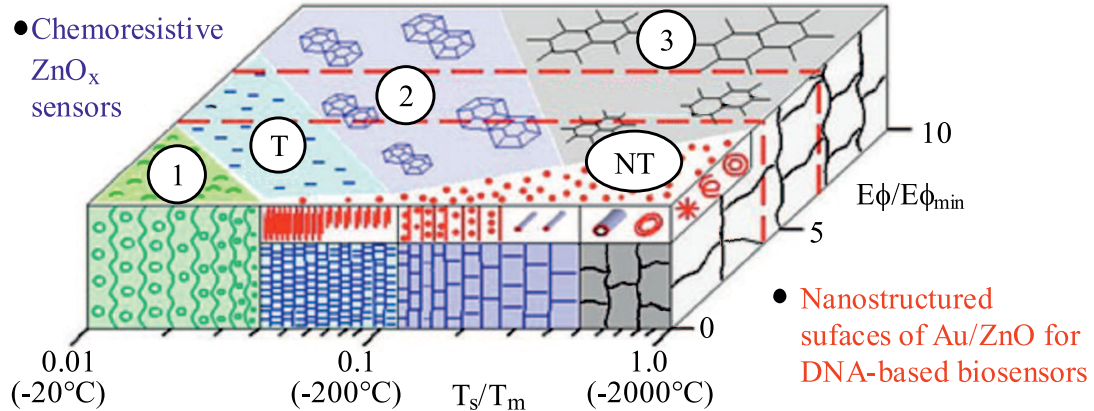

Fig. 2. Our application of sputtered $\mathrm{ZnO}$ thin films in regard to the zone model of their crystalline structure: Zone 1 - porous structure of tapered amorphous or crystalline nanograins separated by voids, Zone T - dense polycrystalline structure of fibrous and nanocrystalline grains, Zone 2 - columnar grain structure, Zone 3 - single-crystal micrograin structure, Zone NT - nanostructures and nanoelements
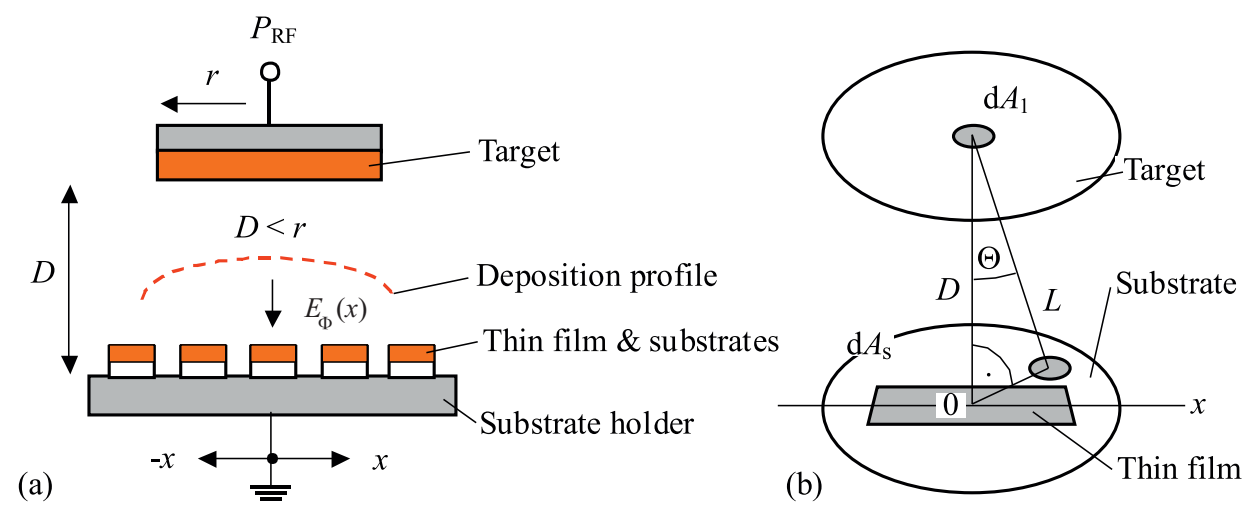

Fig. 3. Arrangement of the diode sputtering system

the working gas plasma or target, (v) ions bombarding the substrate in bias or reactive mode. These effects can cause significant changes in the crystalline structure, surface morphology and chemical stoichiometry of sputtered thin films, ie they can modify their electrical and optical properties.

Structural models based on Thornton's assumptions [4] are well satisfied in the technological approach of sputtering of metals. In the parameter "Ar working gas pressure" he implicitly included collisions between the sputtered and Ar atoms at elevated pressures causing the deposited atoms to arrive at the substrate in randomized directions that promote oblique coating. Therefore to use more physical approach, in addition to substrate temperature Ts, we introduced a total energy flux density $E_{\Phi}\left(\mathrm{W} / \mathrm{m}^{2}\right)$ affecting to the substrate and the growing thin film (Fig. 2). A total energy flux density, by other words power density $E_{\Phi}$, can be expressed by microscopic quantities known from the kinetic theory of gases, lowtemperature plasma physics and the models of sputtering processes. It can be also estimated by macroscopic sputtering parameters like supply RF power, deposition rate, average DC voltage induced on target, flow or pressure of working gases, substrate bias voltage or power [5]. The substrate temperature is normalized to the melting temperature $T_{m}$ of sputtered material, $T_{s} / T_{m}$. The substrate temperatures are usually very far from melting point of $\mathrm{ZnO}\left(T_{m}=1975{ }^{\circ} \mathrm{C}\right)$ during the sputtering that's why we found useful to express $T_{s} / T_{m}$ in logarithmic scale. The ratio of the total energy flux density $E_{\Phi}$ and its minimum value $E_{\Phi \text { min }}$ specified by the sputtering mode and the geometrical arrangement of the sputtering system is $E_{\Phi} / E_{\Phi \min }$. Optimal conditions for deposition of semiconductor oxides and nitrides (ITO, TiN, $\mathrm{ZnO}, \mathrm{ZnO}: \mathrm{N}$, $\mathrm{ZnO}: \mathrm{Al}, \mathrm{ZnO}: \mathrm{Ga}, \mathrm{ZnO}: \mathrm{Sc}$ ) in our diode sputtering system corresponded to the relative total energy flux density $E_{\Phi} / E_{\Phi \min }$ in the range of $4-7, E_{\Phi \min } \sim 1 \times 10^{4} \mathrm{~W} / \mathrm{m}^{2}$, (Fig. 2, dashed lines). 


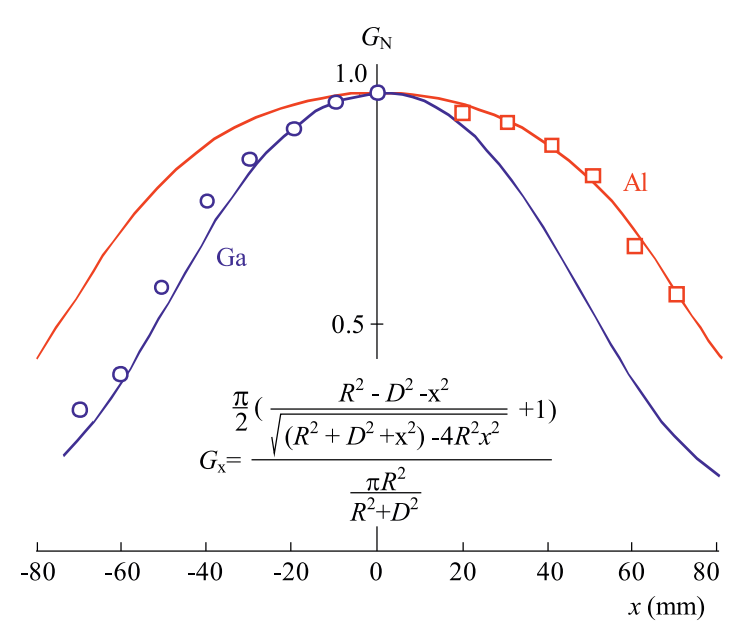

Fig. 4. Experimental and theoretical deposition profiles of $\mathrm{ZnO}: \mathrm{Al}$ target with diameter of $152.4 \mathrm{~mm}$ and $\mathrm{ZnO}$ : Ga target with diameter of $76.2 \mathrm{~mm}$ ergetic particles of various types (negative ions, reflected atoms, secondary electrons) has to be taken into consideration. Corning glass substrates were placed on different positions under the target, in diameter of 6 " $\left(\mathrm{ZnO}+2\right.$ wt. $\left.\% \mathrm{Al}_{2} \mathrm{O}_{3}\right)$ or $4^{\prime \prime}\left(\mathrm{ZnO}+2\right.$ wt. $\left.\% \mathrm{Ga}_{2} \mathrm{O}_{3}\right)$ Fig. 3.

We have applied the model and simulations of spatial distribution of sputtered particles in our diode system (so-called deposition profile) to get continual changes of thin film thicknesses in one deposition run [1].

Our diode system consisting of the plan-parallel arrangement of target and substrate in the distance of $D$ (Fig. 3) with these idealized assumptions:

(a) Material of the target is emitted uniformly from the target area $A_{t}$;

(b) Angular distribution of the intensity of particles rejected from the target (sputtered particle flux $J$ in the direction given by an angle $\Theta$ to the normal of surface) conforms with the Knudsen cosine law [2]

$$
J=J_{0} \cos \Theta
$$

or with its slight modifications, $J_{0}$ is the sputtered flux perpendicular to the target surface;
We used the RF diode sputtering where the bombardment of a growing film during deposition with en-
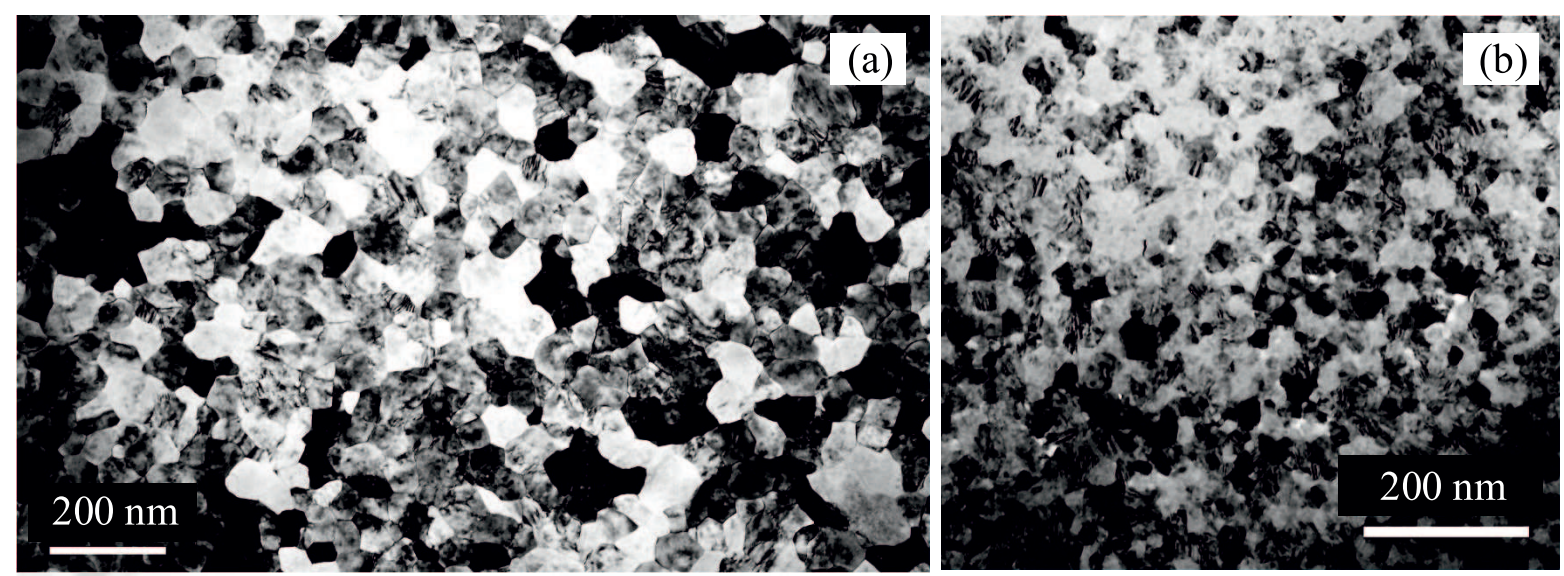

(c)
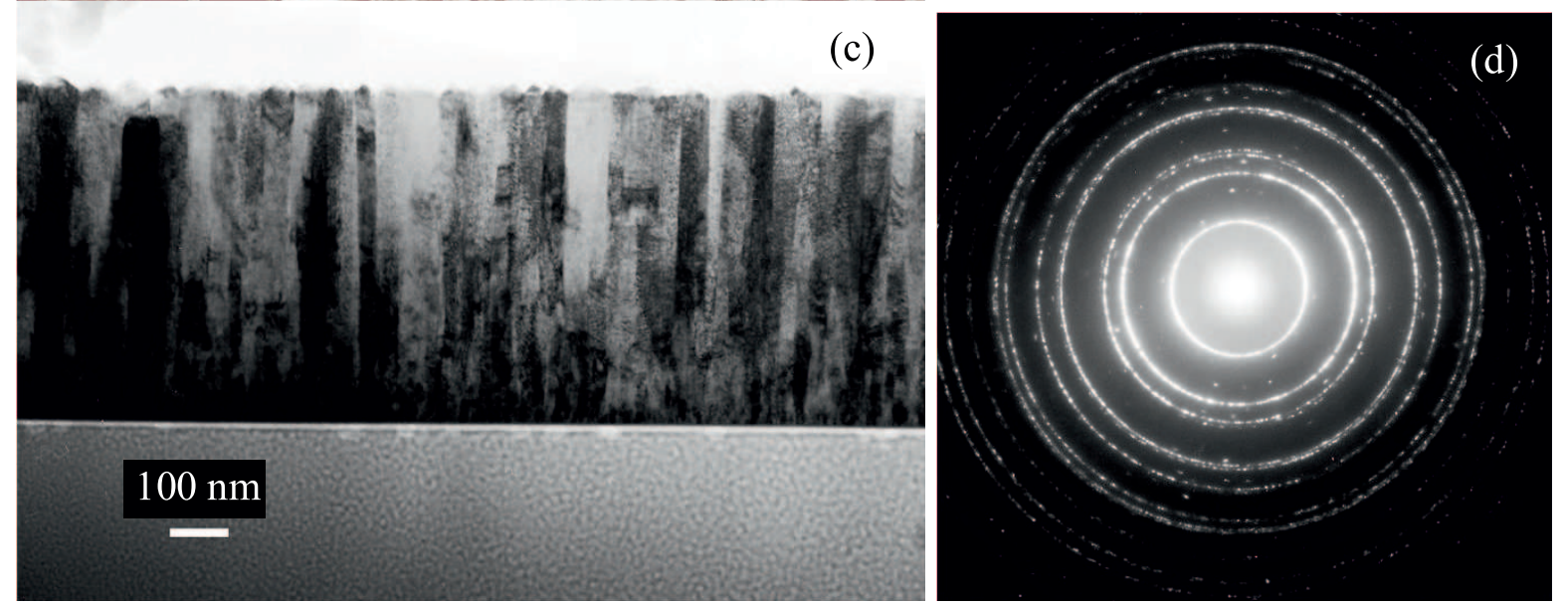

Fig. 5. Changes of structure AZO thin films with the substrate position observed by TEM: (a) grain size 50 nm for middle position,

(b) $20 \mathrm{~nm}$ for peripheral position, (c) cross-section of $\mathrm{ZnO}$ :Al thin film reveals the columnar structure, (d) electron diffraction confirms the hexagonal $\mathrm{ZnO}: \mathrm{Al}$ phase and it reveals the preferential orientation (001) in normal to the film plane direction 

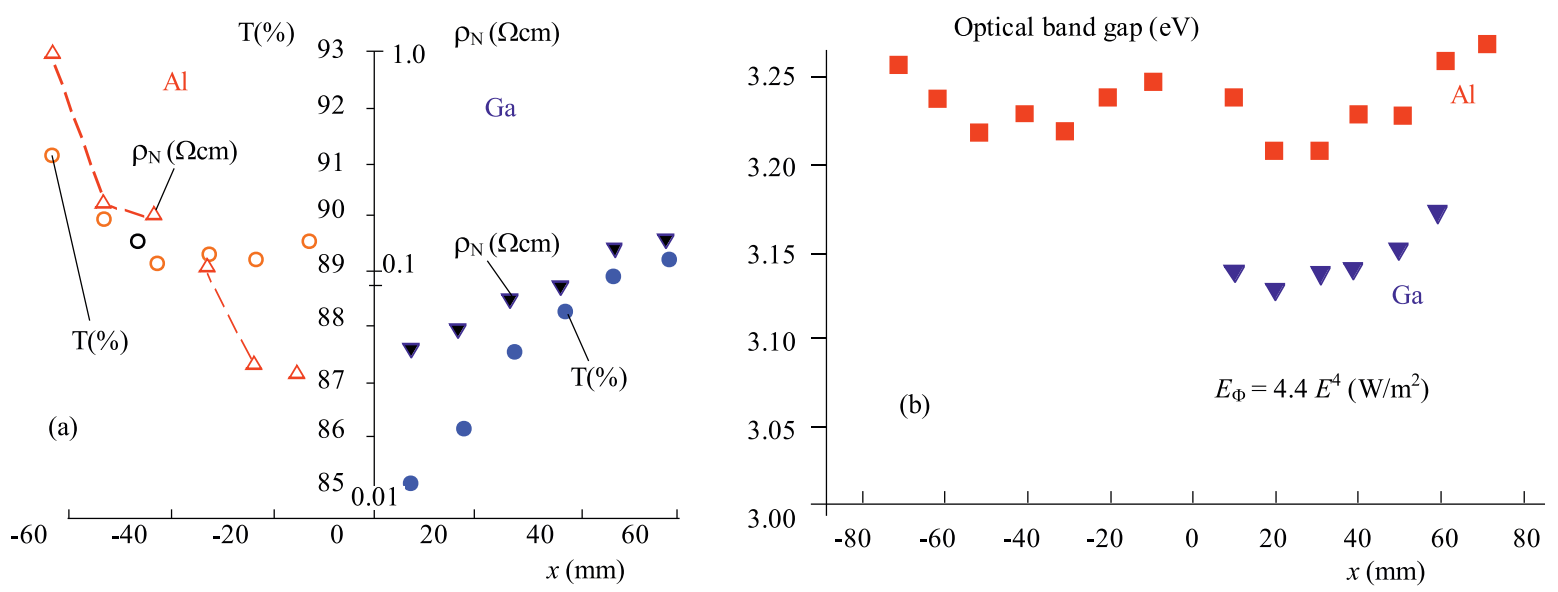

Fig. 6. Changes of properties of $\mathrm{ZnO}: \mathrm{Al}, \mathrm{Ga}$ thin films with the substrate position: (a) transmittance $T$ and resistivity $\rho_{N}$, (b) optical band gap $E_{g}$ 。

(c) Scattering of particles on the way to substrate is neglected;

(d) Accommodation coefficient of particles condensed on the substrate is equal 1 (re-sputtering is not included).

We can get the deposition profile $\mathrm{G}(\mathrm{P})$ in the arbitrary point $\mathrm{P}$ on the substrate

$$
G(P)=\left(\pi / J_{0}\right) \mathrm{d} J / \mathrm{d} A_{S}=\int_{A_{t}} \cos ^{2} \Theta / L^{2} \mathrm{~d} A .
$$

It is useful to normalize the deposition profile $G_{N}(P)$ towards the maximal value of $G(0)$ which is usually the beginning of the co-ordinal system across the substrate

$$
G_{N}(P)=G(P) / G(0) .
$$

Using the $\mathrm{RF}$ diode sputtering in the low-pressure region $(p \leq 1.3 \mathrm{~Pa})$, the mean free path of sputtered particles $\left(\sim 10^{-2} \mathrm{~m}\right)$ is comparable with the distance of target - substrate $\left(4 \times 10^{-2} \mathrm{~m}\right)$ and therefore we can assume "collision-less" regime, particularly for high energetic particles passed through RF discharge. Changes of thin film thicknesses were less then $15 \%$ in the central substrate holder region of diameter $\leq 1 / 3$ of target diameter - at center position its maximal values were $800 \mathrm{~nm}$ ( $\mathrm{ZnO}: \mathrm{Al})$ and $950 \mathrm{~nm}$ ( $\mathrm{ZnO}: \mathrm{Ga})$, Fig. 4. In distances equal to the target radius, the thin film thickness decreased down to $40 \%$ of the maximal value. Sputtering rates followed these dependences and their maximal values in the center were $47 \mathrm{~nm} / \mathrm{min}(\mathrm{ZnO}: \mathrm{Al})$ and $32 \mathrm{~nm} / \mathrm{min}$ ( $\mathrm{ZnO}: \mathrm{Ga}$ ) respectively.

\section{RESULTS AND DISSCUSSION}

Structural, optical and electrical properties of thin films were estimated by XRD analysis, UV/VIS spectrophotometry and electrical four-probe method. They were significantly influenced by the local placement of substrates on the substrate holder. All films were polycrystalline with a strong texture in the [001] direction perpendicular to the substrate, but sputtering in peripheral substrate holder region caused a decrease of structural parameters in comparison with middle position: mean grain size from $50 \mathrm{~nm}$ to $20 \mathrm{~nm}$, Fig. 5, average size of crystallites from $122 \mathrm{~nm}$ to $50 \mathrm{~nm}$, and an increase of compressive biaxial lattice stresses from $-4 \mathrm{GPa}$ to $-6 \mathrm{GPa}$.

In the case of both dopants the resistivity have also varied in the range of $10^{-2}-1 \Omega \mathrm{cm}$ and the optical transmittance of $85-91 \%$, Fig. 6a. On Fig. $6 \mathrm{~b}$ is shown the dependence of the calculated optical band-gap $E_{g}$ of thin films as a function of position on the holder. Courses of optical band-gap dependences on substrate position are copying the transmittance dependences: their values for $\mathrm{ZnO}: \mathrm{Al}$ were in the range $3.24 \mathrm{eV} \pm 0.03$ and for $\mathrm{ZnO}: \mathrm{Ga}$ $3.15 \mathrm{eV} \pm 0.02$. Spatial distributions of both fluxes, sputtered particles and energetic species (Ar ions neutralized at the target and reflected from it, negative oxygen ions coming from sputtered targets and secondary electrons) and their mutual ratios were responsible for both opposite effects on TCO thin film properties: an improvement of composition ( $\mathrm{eg}$ breaking-up oxide compounds of $\mathrm{Al}$, Ga dopands and to replace Zn by them in the lattice) or the degradation of structure ( $e g$ to cause extended defects in the film crystalline structure as intersticials, lattice expansion, grain boundaries). Most of these detrimental effects were reduced by the heating of substrates during sputtering $\left(\sim 200^{\circ} \mathrm{C}\right)$ what has resulted in $\mathrm{ZnO}$ :Al films with low resistivities in order of $10^{-3} \Omega \mathrm{cm}$ and high optical transmittances about $93 \%$ in the range 400-1000 nm. From evaluation of presented results we can conclude that TCO thin films based on $\mathrm{ZnO}$ doped by $\mathrm{Al}$ and prepared by $\mathrm{RF}$ diode sputtering are the most suitable for photovoltaic applications.

\section{CONCLUSIONS}

A novel approach for preparation of strong textured thin films by the sputtering can be exploited in solar cells and in various optoelectronic devices. It has accelerated our investigation in the finding of suitable thin film properties of $\mathrm{ZnO}: \mathrm{Al}$ and $\mathrm{ZnO}$ :Ga. This is also applicable in 
an engineering of the nanoscale morphology, eg for preparation of a new class of optical nanomaterials - sculptured thin films - consisting of shaped, parallel, identical nanowires generally grown by physical vapour deposition techniques.

\section{Acknowledgement}

This contribution is the result of the project implementation National Centre for Research and Application of Renewable Energy Sources (ITMS: 26240120016), supported by the Research \& Development Operational Programme funded by the ERDF. Special thanks to Dr I. Vávra for TEM analysis from IEE, SAS Bratislava.

\section{REFERENCES}

[1] GASPIERIK, P.-VAVRINSKY, E.-SUTTA, P.-TVAROZEK, V.: Simulation of Silicon Thin-Film Solar Cell Structure, 54. Internationales Wissenschaftliches Kolloquium, CD, Ilmenau, Germany, 2009.

[2] KAMINSKY, M.: Atomic and Ionic Impact Phenomena on Metal Surfaces, Springler Verlag, Berlin Heideberg, 1965.
[3] MORKOC, H.-OZGUR, U.: Zinc Oxide - Fundamentals, Materials and Device Technology, WILEY-VCH Verlag GmbH \& Co. KGaA, Weinheim, 2009.

[4] ThORTON, J. A.-HOFFMAN, D. W.: Stress-Related Effects in Thin Films, Thin Solid Films, 171 (1989), 5-1.

[5] TVArozeK, V.-NOVOTNY, I.-SUTTA, P.-FLICKYNGEROVA, S.-SHTEREVA, K.-VAVRINSKY, E. : Influence of Sputtering Parameters on Crystalline Structure of $\mathrm{ZnO}$ Thin Films, Thin Solid Films 515 (2007), 8756-8760.

[6] ZEMAN, M.: Advanced a-Si Solar Cell Technologies: Thin Film Solar Cells: Fabrication, Characterization and Applications (Poortmans, J. Arkhipov, V., eds.), John Wiley \& Sons, New York, 2007, pp. 173-236.

Received 30 June 2010

Soňa Flickyngerová, Vladimír Tvarožek, Pavol Gašpierik. Biographies not supplied.

This work was presented at International Conference Energetika 2010, May 18-20, 2010, Vysoké Tatry - Tatranské Matliare, Slovakia.

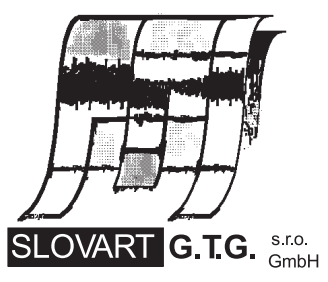

EXPORT - IMPORT
EXPORT - IMPORT

of periodicals and of non-periodically printed matters, books and CD-ROMs

Krupinská 4 PO BOX 152, 85299 Bratislava 5, Slovakia tel: ++421 263839 472-3, fax: ++421 263839485 info@slovart-gtg.sk; http://www.slovart-gtg.sk

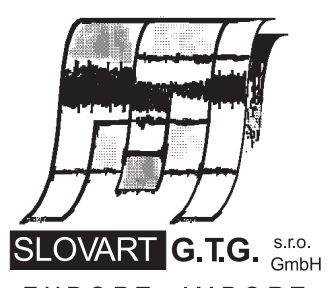

EXPORT - IMPORT 